\title{
Pengaruh Kualitas Layanan Pendidikan, Budaya Sekolah, Citra Sekolah Terhadap Kepuasan Orang Tua
}

\author{
Nobita Triwijayanti ${ }^{1}$, Herry Sanoto ${ }^{2}$, Mila Paseleng ${ }^{3}$ \\ nobita.triwijayanti@uksw.edu ${ }^{1}$, herry.sanoto@uksw.edu ${ }^{2}$, mila.paseleng@uksw.edu ${ }^{3}$ \\ Universitas Kristen Satya Wacana Salatiga ${ }^{1,2,3}$
} The effect of Education Services Quality, School Cultures, School Images
toward Parental Satisfactions

\begin{abstract}
The aim of this study was to find out the effect of education services quality, school cultures, and school images toward parental satisfactions. This study is a quantitative study using path analysis to find out the effect of each variable on parental satisfactions. This study used questionnaires, interviews and documentation instruments. The subjects on this study were parents. The results on this study showed that there were positive influences of educational services quality, school cultures, and school images on parental satisfactions. it shows the effect of $60.7 \%$ and $40.3 \%$ is influenced by other factors. The findings on this study are educational service satisfactions which has the biggest role in parental satisfactions, followed by school cultures and school images.
\end{abstract}

Keywords: Education Services Quality, School Cultures, School Images, Parental Satisfactions

Received date: 17 Januari 2022

Article Info

Revised date: 19 Januari 2022 Accepted date: 27 Januari 2022

\section{PENDAHULUAN}

Pendidikan merupakan elemen utama dalam meningkatkan kualitas diri seseorang (Goldberg et al., 2010). Melalui proses pendidikan seseorang yang tidak mengetahui manjadi tahu. Selain dalam aspek individu, pendidikan merupakan motor dalam meningkatkan kualitas suatu bangsa. Sehingga pendidikan merupakan investasi masa depan suatu bangsa. Pendidikan yang berkualitas dapat mendukung perkembangan suatu bangsa dalam berbagai aspek karena pendidikan menghasilkan sumber daya manusia yang berkualitas dan mampu bersaing dengan sumberdaya manusia dari negaranegara lain. Pendidikan yang baik adalah pendidikan yang berkualitas, namun untuk menjadi investasi masa depan suatu bangsa, pendidikan juga harus diberikan dan dirasakan oleh seluruh warga negara. Tilaar dalam Rasyid (2015) menuliskan bahwa melalui pendidikan suatu bangsa akan hidup secara tangguh dalam masyarakat dunia yang ditandai dengan kehidupan yang penuh dengan tantangan dan komperisi secara ketat.

Mencapai capaian pendidikan yang baik diperlukan proses dan system pendidikan yang berkualitas, yang mampu dalam mewujudkan pendidikan yang memenuhi kebutuhan manusia, menyesuaikan dengan kemajuan jaman, dan mampu selalu berinovasi dalam meningkatkan kualitasnya (Warisno, 2018). Jika kita melihat dari hasil PISA yang diselenggarakan oleh OECD menujukan bahwa negara dengan kualitas pendidikan yang baik memiliki tingkat capaian siswa yang baik. Tes PISA yang dilakukan oleh OECD menguji tentang kemampuan siswa di usia 15 tahun tentang kemampuan literasi Bahasa, literasi matematika dan literasi sains. Yang mana, ketiga aspek tersebut merupakan inti untuk mencapai sumber daya manusia yang berkualitas dan mampu bersaing di abad ke 21. Negara dengan system pendidikan yang baik memiliki skor yang berada diatas skor rata-rata OECD. Indonesia yang merupakan salah satu negara yang turut serta dalam tes PISA hanya mampu berada di peringkat tiga paling bawah dari seluruh peserta tes PISA yang terdiri dari 72 negera (OECD, 2018). Hal tersebut menjadi aspek yang perlu di perhatikan dalam upaya meningkatkan kualitas pendidikan di Indonesia.

Bagian paling kecil dalam system pendidikan salah satunya adalah sekolah, sekolah merupakan pintu awal siswa belajar dan menyerap ilmu pengetahuan. Melalui sekolah seluruh kebijakan nasional berkaitan dengan program, dan kebijakan pendidikan di aplikasikan secara langsung kepada siswa (Arifa \& Prayitno, 2019). Sehingga sejauh mana upaya sekolah dalam mengaplikasikan kebijakan baik 
dari tingkat nasional maupun kebijakan dari tingkat sekolah berdampak langsung kepada siswa. Kualitas sekolah merupakan aspek yang selalu diperhatikan guna menjamin siswa mendapatkan pendidikan yang baik dan berkualitas (Adams, 1993; Wahyoedi et al., 2021). Era abad 21, kualitas sumber daya manusia sangat berpengaruh kepada keberlangsungan bangsa, karena persaingan bukan hanya pada level nasional namun juga pada level internasional (Sri Yustikia, 2019). Sumber daya manusia yang semakin berkualitas akan mempermudah suatu negara untuk melangkah lebih maju.

Kualitas sekolah tidak hanya bergantung kepada kebijakan nasional dan kebijakan sekolah, namun budaya sekolah mampu membentuk tradisi dan ciri khas dari setiap sekolah. Budaya sekolah merupakan nilai, tradisi dan kebijakan sekolah yang dipraktekan oleh semua civitas sekolah (Perspectives on Educational Quality, 2011; Sukadari, 2020). Budaya yang baik dari sekolah dapat meningkatkan kualitas sekolah dan secara langsung berdampak kepada siswa. Hal tersebut secara tidak langsung merupakan aspek yang dapat menjadi keunggulan dari setiap sekolah dengan ciri khas dan tradisi masing-masing.

Orang tua sebagai partner sekolah dalam melaksanakan proses pendidikan memiliki harapan besar terhadap anaknya untuk dapat bersekolah di sekolah yang memiliki citra yang baik. Citra sekolah dilihat berdasarkan kualitas, budaya sekolah yang secara langsung berpengaruh terhadap output siswa yang memiliki kemampuan yang baik dan mampu bersaing di level yang lebih tinggi. Oleh sebab itu aspek kualitas sekolah menjadi sudut pandang utama bagi orang tua dalam menyekolahkan anaknya. Sehingga muncul istilah sekolah favorit yang diindikasikan dengan kualitas pendidikan yang baik dan pastinya memiliki minat siswa untuk bersekolah disana yang banyak. Berdasarkan hasil penjabaran diatas maka peneliti akan meneliti bagaimana Pengaruh Kualitas Layanan Pendidikan, Budaya Sekolah, Citra Sekolah terhadap Kepuasan Orang Tua.

Berdasarkan latar belakang dan permasalahan yang telah dipaparkan di atas, maka penelitian ini bertujuan untuk mengenal secara pasti: 1) pengaruh kualitas layanan pendidikan terhadap kepuasan orang tua; 2) pengaruh budaya sekolah terhadap kepuasan orang tua; dan 3) pengaruh citra sekolah terhadap kepuasan orang tua.

\section{KAJIAN PUSTAKA}

Kotler dan Keller (2009) kepuasan konsumen adalah merupakan perasaan senang atau kecewa seseorang yang muncul setelah membandingkan antara kinerja atau hasil yang diharapkanya. Lalu menurut Fandy Tjiptono (2019) kepuasan pelanggan adalah perasaan senang atau kecewa seseorang yang muncul setelah membandingkan antara persepsi terhadap kinerja (hasil) suatu produk dengan harapan-harapanya. Kepuasan pelanggan menurut Yulianto (2011) yaitu perbedaan antara yang diharapkan pelanggan (nilai harapan) dengan realisasi yang diberikan penyedia jasa dalam usaha memenuhi harapan konsumen (nilai presepsi) apabila nilai harapan sama dengan nilai presepsi, maka konsumen puas dan apabila nilai harapan lebih kecil dari nilai presepsi, makan konsumen sangat puas. Menurut Elliot dan Healy (2001) indikator dari kesesuaian harapan dari realisasi mencakup fokus pada siswa (focus on student), lingkungan akademik (academic environment), keaktifan mengajar (teaching affectivity).

Kualitas layanan adalah kemampuan pihak penyedia jasa dalam memenuhi kebutuhan dan keinginan pelanggan sesuai dengan ekspektasi atau harapan pelanggan. Sebagai penyedia jasa pendidikan, maka sekolah haruslah mampu memenuhi kebutuhan dan keinginan orang tua/wali peserta didik sesuai dengan harapan, karena kualitas layanan merupakan salah satu faktor keberhasilan sebuah sekolah. Menurut Parasuraman, Zeithaml, dan Berry dalam Tjiptono (2011) terdapat lima dimensi kualitas layanan yang dijadikan pedoman oleh pelanggan dalam menilai kualitas layanan, yaitu: 1) Berwujud (Tangible), berupa penampilan fasilitas fisik, peralatan, dan personil, 2) Empati (Emphaty), syarat untuk peduli, memberi perhatian pribadi bagi pelanggan, 3) Keandalan (Reliability), kemampuan untuk melaksanakan jasa yang dijanjikan dengan tepat dan terpercaya, 4) Keresponsifan (Responsiveness) merupakan kemauan untuk membantu pelanggan dan memberikan jasa dengan cepat atau tanggap, 5) Keyakinan (Assurance) mencakup pengetahuan dan kesopanan karyawan serta kemampuan mereka untuk menimbulkan kepercayaan dan keyakinan.

Budaya sekolah dapat dimaknai sebagai suasana kehidupan sekolah dimana peserta didik berinteraksi dengan sesama, guru dengan guru, konselor dengan peserta didik, antar tenaga kependidikan, antara tenaga kependidikan dengan pendidik dan peserta didik, dan antar anggota 
Pengaruh Kualitas Layanan Pendidikan, Budaya Sekolah, Citra Sekolah Terhadap Kepuasan Orang Tua (Nobita Triwijayanti, Herry Sanoto, Mila Paseleng)

kelompok masyarakat dengan warga sekolah. Di dalam budaya sekolah terdapat pola-pola yang mendalam, kepercayaan nilai, dan tradisi yang terbentuk dari rangkaian, kebiasaan dan sejarah sekolah, serta cara pandang dalam memecahkan persoalan-persoalan yang ada di sekolah. Menurut Robbins (2006) budaya organisasi memiliki beberapa indikator, yaitu innovation and risk taking, attention to detail, outcome orientation, people orientation, team orientation, aggressiveness, dan stability.

Citra sekolah dapat dimaknai dengan kesan, gambaran atau persepsi dari masyarakat yang didapatkan dari pengalaman, kepercayaan, perasaan dan pengetahuan masyarakat terhadap sekolah. Sehingga kualitas layanan, sarana prasarana sekolah, program sekolah dan budaya sekolah dapat mempengaruhi citra sekolah. Citra merupakan hal yang absrak, tidak dapat digambarkan dan tidaklah nyata. Namun citra dapat diukur dan diubah. Menurut Zhang dan Shirley Harrison dalam Fitriani (2012), terdapat empat dimensi pada citra, yaitu personality, value, communication, dan likeability. Personality merupakan sikap dalam mempertanggungjawabkan layanan apabila terjadi masalah terhadap pelanggan. Value yaitu nilai moral, etika dan kepedulian karyawan dalam melakukan pelayanan. Communication merupakan kemudahan penyebaran informasi kepada pelanggan. Likeability dapat dimaknai dengan keramahan dan perhatian secara personal terhadap pelanggan.

\section{METODE PENELITIAN}

Metode penelitian yang digunakan dalam penelitian ini adalah metode penelitian kuantitatif dengan menganalisis pengaruh kualitas layanan pendidikan, budaya sekolah, citra sekolah terhadap kepuasan orang tua. Metode penelitian kuantitatif adalah metode penelitian yang digunakan untuk meneliti pada kondisi obyek hasil eksperimen (tidak alamiah) terhadap populasi atau sampel tertentu, pengumpulan data menggunakan instrumen dan olahan data menggunakan uji statistik digunakan untuk menguji hipotesis (Sukestiyarno, 2020).

Instrumen yang digunakan dalam penelitian adalah angket yang disusun berdasarkan pada aspek kualitas layanan sekolah, budaya sekolah, citra sekolah, dan kepuasan orang tua. Instrumen yang dikembangkan telah melalui proses validasi oleh validator ahli yang dengan memenuhi kriteria valid digunakan dalam proses penelitian. Sedangkan untuk reliabilitas butir angket digunakan rumus Cronbach Alpha sehingga diperoleh 5 pernyataan yang tidak memenuhi kriteria dan dihilangkan dan butir angket yang memenuhi kriteria reliabel sebanyak 60 pernyataan.

Teknik analisis uji menggunakan analisis data statistik deskriptif dengan menggunakan uji jalur untuk mendeskripsikan pengaruh setiap variabel indepen terhadap variabel dependen. Variabel dependen dalam penelitian ini adalah kepuasan orang tua, sedangkan variabel independen dalam penelitian ini adalah kualitas layanan sekolah, budaya sekolah, citra sekolah dan kepuasan orang tua.

Subjek dalam penelitian ini adalah orang tua siswa yang terdiri dari 40 orang yang merupakan orang tua siswa SMP Kristen Satya Wacana. Teknik pemilihan subjek dalam penelitian ini adalah dengan menggunakan Teknik random sampling, yaitu dalam proses pemilihan subjek, setiap subjek dalam populasi memiliki kesempatan yang sama untuk dipilih menjadi sampel. Subjek diberikan angket berkaitan dengan kualitas layanan sekolah, budaya sekolah, citra sekolah dan kepuasan orang tua. Adapun indikator kualitas pelayanan, budaya sekolah, citra sekolah dan kepuasan orang tua dijabarkan dalam beberapa aspek sebagai berikut

Tabel 1. Indikator Instrumen Penelitian

\begin{tabular}{llll}
\hline Kualitas Layanan Sekolah & \multicolumn{1}{c}{ Budaya Sekolah } & Citra Sekolah & Kepuasaan Orang Tua \\
\hline Tangible & Innovation and risk taking & Personality & Focus on student \\
& & & \\
Emphaty & Attention to detail & Value & Academic environment \\
Reliability & Outcome orientation & Communication & Teaching affectivity \\
Responsiveness & People orientation & Likeability & \\
Assurance & Team orientation & & \\
& Aggressiveness & & \\
& Stability & & \\
\hline
\end{tabular}

Sedangan kajian yang menjadi variabel dalam penelitian ini digambarkan dalm tabel 2 berikut. 
Tabel 2. Keterangan Variabel dalam Penelitian

\begin{tabular}{cl}
\hline Simbol & \multicolumn{1}{c}{ Keterangan } \\
\hline X1 & Kualitas Layanan Sekolah \\
X2 & Budaya Sekolah \\
X3 & Citra Sekolah \\
Y & Kepuasaan Orang Tua \\
\hline
\end{tabular}

Dalam rangka memandu proses penelitan dan melakukan analisis hasil penelitian, maka dirumuskan hipotesis penelitian berikut: 1) terdapat pengaruh kualitas layanan pendidikan terhadap kepuasan orang tua; 2) terdapat pengaruh budaya sekolah terhadap kepuasan orang tua; dan 3) terdapat pengaruh citra sekolah terhadap kepuasan orang tua.

\section{HASIL PENELITIAN DAN PEMBAHASAN}

\section{Hasil Penelitian}

Hasil angket dan tes kemampuan literasi matematis siswa dilakukan uji regresi sehingga menghasilkan output sebagai berikut.

\section{Pengaruh Kualitas Layanan Pendidikan, Budaya Sekolah, Citra Sekolah terhadap Kepuasan} Orang Tua

\begin{tabular}{|c|c|c|c|c|c|c|}
\hline \multicolumn{7}{|c|}{ Coefficients $^{a}$} \\
\hline \multirow[b]{2}{*}{ Model } & & \multicolumn{2}{|c|}{ Unstandardized Coefficients } & \multirow{2}{*}{$\begin{array}{c}\text { Standardized } \\
\text { Coefficients } \\
\text { Beta }\end{array}$} & \multirow[b]{2}{*}{$\mathrm{t}$} & \multirow[b]{2}{*}{ Sig. } \\
\hline & & B & Std. Error & & & \\
\hline \multirow[t]{4}{*}{1} & (Constant) & -2.603 & 11.104 & & -.234 & .816 \\
\hline & Budaya_Sekolah & .257 & .109 & .282 & 2.354 & .024 \\
\hline & Citra_Sekolah & .327 & .115 & .316 & 2.855 & .007 \\
\hline & $\begin{array}{l}\text { Kualitas_Layanan_Pendi } \\
\text { dikan }\end{array}$ & .450 & .128 & .429 & 3.529 & .001 \\
\hline
\end{tabular}

a. Dependent Variable: Kepuasan_Orang_Tua

\section{Gambar 1. Output SPSS Coefficient}

Berdasarkan hasil uji statistik menunjukan bahwa pada output regresi menenujukan bahwa Pengaruh Kualitas Layanan Pendidikan memiliki pengaruh terhadap Kepuasan Orang Tua dengan nilai sig 0,001<0,05 sehingga H0 ditolak dan H1 diterima. Aspek Budaya Sekolah juga memiliki pengaruh terhadap Kepuasan Orang Tua dengan nilai sig 0,24<0,05 sehingga H0 ditolak dan H1 diterima. Sedangan untuk Citra Sekolah juga memiliki pengaruh terhadap Kepuasan Orang Tua dengan nilai sig 0,007 <0,05 sehingga H0 ditolak dan H1 diterima. Pengaruh Kualitas Layanan Pendidikan, Budaya Sekolah, Citra Sekolah berpengaruh terhadap Kepuasan Orang Tua.

\begin{tabular}{|c|c|c|c|c|}
\hline \multicolumn{5}{|c|}{ Model Summary } \\
\hline Model & $\mathrm{R}$ & R Square & $\begin{array}{l}\text { Adjusted R } \\
\text { Square }\end{array}$ & $\begin{array}{l}\text { Std. Error of } \\
\text { the Estimate }\end{array}$ \\
\hline 1 & $.779^{\mathrm{a}}$ & .607 & .574 & 5.706 \\
\hline
\end{tabular}

Gambar 2. Output SPSS Model Summary

Berdasarakan data R Square diperolah 0,607 atau 60,7\%, yang berarti kontribusi dari Kualitas Layanan Pendidikan, Budaya Sekolah, dan Citra Sekolah terhadap Kepuasan Orang Tua sebesar $60,77 \%$. Sisanya sebesar $39,3 \%$ diperngaruhi oleh factor lainnya. Sehingga nilai $e 1=\sqrt{1-0,607}=$ 0,6268 .

Nilai standar koefisien Kualitas Layanan Pendidikan (beta $X 1=0,429$ ), Budaya Sekolah (koefisien beta $X 2=0,282$ ) dan Citra Sekolah (beta $X 3=0,316$ ). Sehingga dihasilkan diagram jalur sebagai berikut. 
Pengaruh Kualitas Layanan Pendidikan, Budaya Sekolah, Citra Sekolah Terhadap Kepuasan Orang Tua (Nobita Triwijayanti, Herry Sanoto, Mila Paseleng)

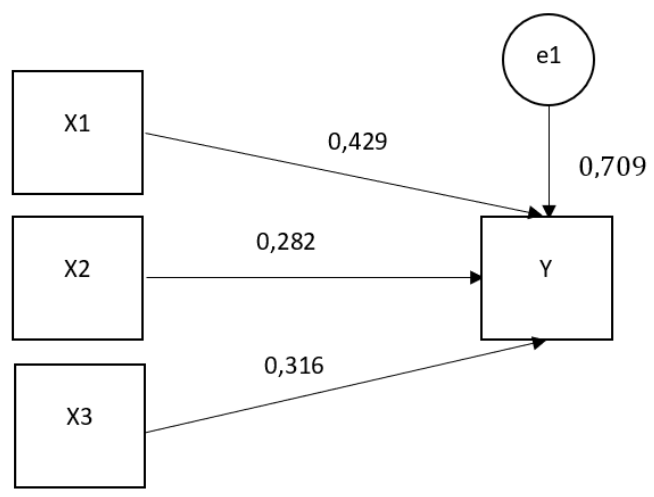

Gambar 3. Diagram jalur Kualitas Layanan Pendidikan, Budaya Sekolah, Citra Sekolah dan Kepuasan

Pengujian Hipotesis

Pengaruh X1 terhadap Y

Berdasarkan data yang diperoleh dari pengujian di atas menunjukan bahwa nilai $\operatorname{sig} X 1=$ $0,001<0,05$. Hal ini berarti terdapat pengaruh langsung X1 terhadap Y. Dengan besar koefisien pengaruh langsung Kualitas Layanan Pendidikan (X1) terhadap Kepuasan Orang Tua (Y) adalah 0,429. Pengaruh X2 terhadap Y

Berdasarkan data yang diperoleh dari pengujian diaas menunjukan bahwa nilai $\operatorname{sig} X 2=$ $0,024<0,05$. Hal ini berarti terdapat pengaruh langsung X2 terhadap Y. Dengan besar koefisien pengaruh langsung Budaya Sekolah (X2) terhadap Kepuasan Orang Tua (Y) adalah 0,282.

\section{Pengaruh X3 terhadap Y}

Berdasarkan data yang diperoleh dari pengujian diaas menunjukan bahwa nilai sig $X 3=$ $0,007<0,05$. Hal ini berarti terdapat pengaruh langsung X3 terhadap Y. Dengan besar koefisien pengaruh langsung Citra Sekolah (X3) terhadap Kepuasan Orang Tua (Y) adalah 0,316.

Berdasarkan hasil uji SPSS menujukan bahwa kualitas layanan pendidikan, budaya sekolah dan citra sekolah berpengaruh positif sebesar $60.7 \%$. Dengan kontribusi terbesar adalah kualitas layanan pendidikan, kemudian citra sekolah, dan yang terakhir adalah budaya sekolah.

\section{Pembahasan}

Hasil pengujian menunjukan bahwa terdapat pengaruh antara Kualitas Layanan Pendidikan, Budaya Sekolah dan Citra Sekolah terhadap Kepuasan Orang tua yaitu sebesar 60,7\%. Hal tersebut menunjukan bahwa terdapat peran kualitas pelayanan sekolah, budaya sekolah dan citra dari sekolah yang mempengaruhi persepsi orang tua. Sesuai dengan penelitian (Skallerud, 2011)bahwa kepuasaan orang tua terhadap sekolah dipengaruhi oleh orientasi orang tua, kualitas pembelajaran, lingkungan yang aman, guru yang baik, kualitas layanan pendidikan, dan budaya sekolah yang secara langsung berdampak kepada reputasi sekolah. Kualitas layanan pendidikan yang baik menciptakan proses pembelajaran yang berkualitas dan siswa dapat memperoleh informasi dan ilmu pengetahuan dengan baik, sehingga tujuan pembelajaran akan mudah tercapai (Winahyuningsih \& Edris, n.d.) Kepuasaan orang tua terhadap sekolah secara langsung muncul ketika anaknya mampu dengan baik memperoleh prestasi dan memiliki kemampuan yang meningkat (Friedman et al., 2007)

Selain kualitas pelayanan sekolah, budaya sekolah juga berdampak ke dalam banyak aspek dalam proses pembelajaran yaitu meliputi kompetensi guru, kompetensi produktif siswa, dan kompetisi positif siswa (Ramli, 2013) Budaya sekolah yang baik menumbuhkan karakter siswa yang baik, sehingga menjadikan budaya di sekolah (Ansar et al., 2020; Manurung et al., 2018). Sehingga hal tersebut berkontribusi dalam membentuk persepsi orang tua. Budaya sekolah yang baik akan mewujudkan kepuasaan orang tua dalam menyekolahkan anaknya di sekolah tersebut, namun jika budaya sekolah yang kurang baik akan berpengaruh pada kepuasaan orang tua yang menurun. Sedangkan kualitas layanan pendidikan dan budaya sekolah secara tidak langsung membentuk citra sekolah di masyarakat(Fredy et al., 2019) Citra sekolah yang terbangun di dalam masyarakat secara tidak langsung menghasilkan persepsi tentang kualitas sekolah yang bersangkutan. Penelitian (Kuswanto et al., 2018) menyatakan bahwa kualitas layanan dan citra sekolah berpengaruh secara signifikan terhadap kepuasan dan loyalitas selurug stakeholder sekolah, yang di dalamnya termasuk orang tua siswa. 
Hasil penelitian menunjukan bahwa terdapat 39,3\% kepuasaan orang tua terhap sekolah dipengaruhi oleh factor lain. Aspek lain yang berpengaruh dalam membentuk kepuasan orang tua adalah citra sekolah. Penelitian (Sulak et al., 2018; Xanthavanij \& Eamoraphan, 2019) menyatakan bahwa kepuasaan orang tua terhadap sekolah terdiri dari beberapa aspek yang meliputi fasilitas sekolah, bahan pembelajaran, keamanan, rasio guru dan siswa, kualitas guru, proses pembelajaran, dan output hasil belajar. Sehingga banyak aspek dan variabel yang mempengaruhi bagaimana persepsi orang tua kepada sekolah dapat terbentuk. Sehingga dalam mencapai kepuasaan orang tua siswa yang positif dipengaruh banyak aspek yang komplek yang meliputi segi fasilitas sekolah, proses pembelajaran dan output siswa.

\section{KESIMPULAN DAN SARAN}

Kesimpulan dalam penelitian ini menunjukan bahwa kualitas pelayanan sekolah, budaya sekolah, dan citra sekolah berpengaruh positif terhadap kepuasaan orang tua. Dengan tingkat kepuasaan sebesar $60,7 \%$. Sedangkan terdapat 39,3\% dipengaruhi oleh aspek lain yaitu meliputi tingkat keamanan sekolah, kualitas guru, proses pembelajaran, dan output siswa dalam belajar di sekolah. Temuan dalam penelitian adalah dalam kualitas layanan pendidikan memiliki pengaruh paling besar, disusul dengan citra sekolah dan budaya sekolah.

Saran dalam penelitian ini bagi pihak sekolah adalah tingkatkan kualitas pelayanan di sekolah dengan terus berinovasi dalam proses pembelajaran, fasilitas dan meningkatkan kemampuan guru untuk mempertahankan ataupun meningkatkan kepuasan orang tua peserta didik. Bagi peneliti selanjutnya, penelitian ini dapat dijadikan rujukan untuk penelitian berikutnya terkait dengan aspek kepuasan orang tua terkait dengan pelayanan pembelajaran di sekolah.

\section{UCAPAN TERIMA KASIH}

Terima kasih kepada perangkat sekolah dan orang tua/wali peserta didik di SMP Kristen Satya Wacana yang telah mendukung pelaksanaan penelitian ini.

\section{DAFTAR PUSTAKA}

Abdul Rasyid. (2015). Effects of Ownership Structure, Capital Structure, Profitability and Company's Growth TowardsFirm Value, International Journal of Business and Management Invention, Vol. 4, pp. 25-31, www.ijbmi.org

Adams, D. (1993). Defining quality in education. Improving Educational Quality Project, Biennial $R(1), 14$

Ansar, Irmawanty, \& Rukman, W. Y. (2020). Pengaruh budaya sekolah terhadap pembentukan karakter siswa Ansar Irmawanty Wira Yustika Rukman Pendahuluan Metode Penelitian. 1(1).

Arifa, F. N., \& Prayitno, U. S. (2019). Peningkatan Kualitas Pendidikan: Program Pendidikan Profesi Guru Prajabatan dalam Pemenuhan Kebutuhan Guru Profesional di Indonesia. Aspirasi: Jurnal Masalah-Masalah Sosial, 10(1), 1-17. https://doi.org/10.46807/aspirasi.v10i1.1229

Elliot, K. M., \& Healy M. A. (2001). Key factors influencing student satisfaction related to recruitment and retention. Journal of Marketing for Higher Education, 10, 1-11.

Fredy, F., Tembang, Y., \& Purwanty, R. (2019). Analisis Kepuasan Orangtua dan Siswa terhadap Kualitas Layanan Pendidikan Dasar. Musamus Journal of Primary Education, 2(1), 59-66. https://doi.org/10.35724/musjpe.v2i1.1874

Friedman, B. A., Bobrowski, P. E., \& Markow, D. (2007). Predictors of parents' satisfaction with their children's school. Journal of Educational Administration, 45(3), 278-288. https://doi.org/10.1108/09578230710747811

Goldberg, L. R., Parham, D. F., Coufal, K. L., Maeda, M., Scudder, R. R., \& Sechtem, P. R. (2010). Peer Review: The Importance Of Education For Best Practice. Journal of College Teaching \& Learning (TLC), 7(2). https://doi.org/10.19030/tlc.v7i2.91 
Pengaruh Kualitas Layanan Pendidikan, Budaya Sekolah, Citra Sekolah Terhadap Kepuasan Orang Tua (Nobita Triwijayanti, Herry Sanoto, Mila Paseleng)

Kuswanto, K., Maemunah, M., \& Putra, R. D. (2018). Pengaruh Kualitas Layanan Dan Citra Sekolah Terhadap Loyalitas Stakeholder Sekolah Islam Al-Falah Kota Jambi. JURNAL PENDIDIKAN EKONOMI: Jurnal Ilmiah Ilmu Pendidikan, Ilmu Ekonomi Dan Ilmu Sosial, 12(2), 283. https://doi.org/10.19184/jpe.v12i2.8364

Kotler dan Keller. (2009). Manajemen Pemasaran. Jilid I. Edisi ke 13 Jakarta: Erlangga

Manurung, D. J., Suntoro, I., \& Yanzi, H. (2018). Pengaruh Budaya Sekolah Dan Lingkungan Sekolah Terhadap Pembentukan Karakter Siswa Di SMP. Jurnal Kultur Demokrasi, 3.

OECD. (2018). What 15-year-old students in Indonesia know and can do. Programme for International Student Assessment (PISA) Result from PISA 2018, 1-10.

Perspectives on Educational Quality. (2011). 1. https://doi.org/10.1007/978-94-007-0926-3

Putri Fitriani. (2012). "Pengaruh Kegiatan Corporate Social Responsibility Terhadap Citra Perusahaan". (Universitas Indonesia).

Ramli. (2013). Pengaruh Budaya Sekolah Terhadap Kompetensi Produktif Peserta Didik Smk Negeri Sumatera Barat. Cakrawala Pendidikan, O(2), 307-314. https://doi.org/10.21831/cp.v0i2.1489

Robbins, Stephen. (2006). Perilaku Organisasi, Prentice Hall, edisi kesepuluh.

Skallerud, K. (2011). School reputation and its relation to parents' satisfaction and loyalty. International Journal of Educational Management, 25(7), 671-686. https://doi.org/10.1108/09513541111172081

Sri Yustikia, N. W. (2019). Pentingnya Sarana Pendidikan Dalam Menunjang Kualitas Pendidikan Di Sekolah. Guna Widya: Jurnal Pendidikan Hindu, 4(2), 1. https://doi.org/10.25078/gw.v4i2.1053

Sukadari. (2020). Peranan Budaya Sekolah Dalam Meningkatkan Mutu Pendidikan. Jurnal Exponential, 75-86.

Sukestiyarno. (2020). Metode Penelitian Pendidikan. UNNES PRESS.

Sulak, S. A., Tutuncu, K., \& Koklu, M. (2018). An Investigation of Students, Parents and Teachers' Satisfaction in Science High Schools in Konya Province in Terms of Some Variabilities. Journal of Education and Training, 5(2), 47. https://doi.org/10.5296/jet.v5i2.13308

Fandy, Tjiptono,. (2011) Service Management Mewujudkan Layanan Prima. Edisi. 2. Yogyakarta

Wahyoedi, S., Saparso, S., Tecoalu, M., \& Winoto Tj, H. (2021). The Effect of Service Quality, Learning Quality, and Promotion Strategy on Parents' Decisions in Choosing ABC Primary Schools. Budapest International Research and Critics Institute (BIRCI-Journal): Humanities and Social Sciences, 4(1), 999-1005. https://doi.org/10.33258/birci.v4i1.1701

Warisno, A. (2018). Implementing a Quality Learning in Schools. Ar Raniry : International Journal of Islamic Studies, 5(1), 1-12.

Winahyuningsih, P., \& Edris, M. (n.d.). Pengaruh Pembelajaran Dan Kualitas Pelayanan Terhadap Kepuasan Dan Loyalitas Mahasiswa Universitas Muria Kudus. 1-18.

Xanthavanij, P., \& Eamoraphan, S. (2019). A Comparative Study Of Parental Satisfaction With The Quality Of Education According To Their Demographics In Palina Kindergarten, Bangkok, Thailand. 99-107.

Yulianto. (2011). Dasar-dasar Manajemen Jasa, ed. 10. Jakarta, Salemba Empat. 